\section{Using Advanced CAM-Systems for Optimized HSC-Machining of Complex Free Form Surfaces \\ schuetzer@unimep.br} Laboratory for Computer Application in Design and Manufacturing

Rod. Luis Ometto (SP 306), Km1 13451-900 Santa Bárbara d'Oeste, SP. Brazil

\author{
Eberhard Abele \\ abele@ptw.tu-darmstadt.de \\ Darmstadt University of Technology \\ Institute of Production Management, Technology \\ and Machine Tools \\ Petersenstr. 30 \\ 64287 Darmstadt. Germany
}

Carsten Stroh

stroh@ptw.tu-darmstadt.de

\section{Caspar von Gyldenfeldt \\ gyldenfeldt@ptw.tu-darmstadt.de}

High speed cutting (HSC) offers the opportunity to significantly reduce machining times as well as to minimize manual rework for complex free form surfaces in the die and mould making industry. To achieve the best results it is also necessary to apply HSC-suitable machining strategies to perform optimal high speed milling operations. This paper presents a method to use free form features to improve the automatic generation of high speed machining information for specific geometric areas to create HSC free form manufacturing features. By examining the geometrical and topological information of the work piece's virtual model, the feature elements can be extracted and joined with the required information. This covers several important high speed cutting aspects in the CAM and process stability of different strategies. Using this approach the programming time to produce HSC appropriate tool paths is reduced significantly, while it is quality is secured. Keywords: HSC machining, CAM systems, feature technology system, like optimal technology and strategy suggestion, machining safety requirements

\section{Introduction}

High Speed Cutting is spread and accepted widely in industry as an efficient and productive machining technique (Klocke, Markworth and Knodt, 2001), (Schulz, 2001). However, still remains a lack of implementation of the HSC knowledge and its specific requirements in current $\mathrm{CAD} / \mathrm{CAM}$ systems. A survey (Klocke, Markworth and Knodt, 2001) showed that the relationship between programming time and machining time changes dramatically when using high speed cutting, especially for complex free form surfaces. For conventional machining the milling time is the longest time consuming part of the chain CAM process (NC programming) and NC machining. For HSC-machining the NCprogramming time surmounts the machining time by factor 2 to 3 .

This is mainly caused by the fact that optimal HSC machining of complex free form surfaces requires specific strategies for different sections of the work piece. At the moment the additional effort for generating HSC suitable NC programs is very large. Therefore, in practical application a trade-off between programming time and acceptable cutting conditions has to be found. As a compromise often a zig-zag cutting strategy with a $45^{\circ}$ cut direction is selected for many applications (see Figure 1). This will yield a machining operation easy and fast to program combined with an average surface quality and process stability.

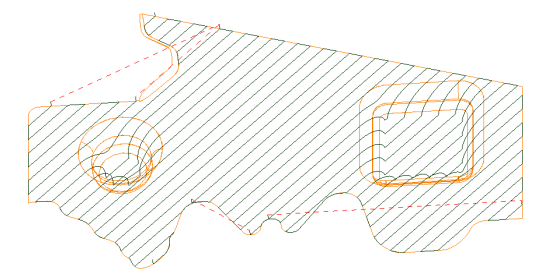

Unfortunately, by this a lot of the benefits of HSC cutting are sacrificed for the minimization of programming time. Figure 2 quantifies in detail the different programming times for the various levels towards HSC appropriate NC-programming. The test was performed using a demonstration part for die and mould making. This reference work piece consists of typical complex free form surface elements of the die and mould making industry.

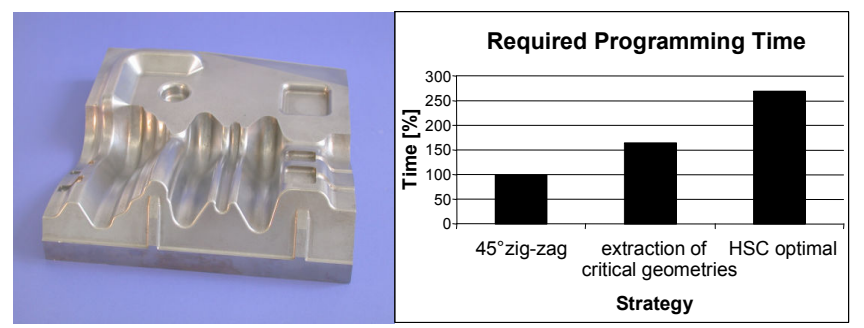

Figure 2. Reference work piece programming time of different machining strategies.

It can be seen that the HSC appropriate NC programming takes significantly more time than conventional programming. Therefore, a method for time efficient HSC appropriate NC programming of complex free form surfaces is needed.

Reducing the time for NC programming means, that the CAM system suggests automatically which regions of the work piece should be machined with which tool, strategy and cutting parameters. The difficulty of this task demonstrates Table 1. It shows for the benchmark part $(300 \times 300 \mathrm{~mm}$; GG-25; HB 285) the obtained results, when the part was machined with different cutting strategies. It can be seen, that the selection of the strategy has significant impact on the milling time and the machined surface quality.

Figure 1. Zig-Zag cutting strategy with $45^{\circ}$ cut direction.

Paper accepted March, 2007. Technical Editor: Anselmo E. Diniz. 
Table 1. Influence of strategy and programming time.

\begin{tabular}{|l|c|c|c|}
\hline \multicolumn{1}{|c|}{ Strategy } & A & B & C \\
\hline Programming time & $5,5 \mathrm{~h}$ & $4,0 \mathrm{~h}$ & $5,0 \mathrm{~h}$ \\
\hline Machining time & $6,0 \mathrm{~h}$ & $24,0 \mathrm{~h}$ & $5,0 \mathrm{~h}$ \\
\hline Result & good & poor & very good \\
\hline
\end{tabular}

Strategy $\mathrm{A}$ and $\mathrm{C}$ were using special cutting patterns for different extra defined cut regions, while with strategy B it was mainly cutting with a fixed angle operation across the whole work piece.

\section{High Speed Cutting}

Regarding the requirements to realize HSC machining, the cutting technology defines the process. Five to ten times higher cutting speeds - compared to conventional machining - have to be realized. For milling, this means that also five to ten times higher spindle speeds will be used. To keep the feed per tooth constant, compared to conventional machining, the feed rate has to be increased in the same ratio. Out of this results higher dynamic performance is required on the machine tool. Machines supplying highly dynamic drives, for example with linear motors, are therefore used for High Speed Cutting, which have acceleration rates of up to $20 \mathrm{~m} / \mathrm{s}^{2}$ and feed rates up to $100 \mathrm{~m} / \mathrm{min}$, like the Hidyn II, developed by the PTW at the Technical University Darmstadt, shown in Figure 3 , which are suitable for the high requirements of HSC machining (Abele and Bork, 2001).

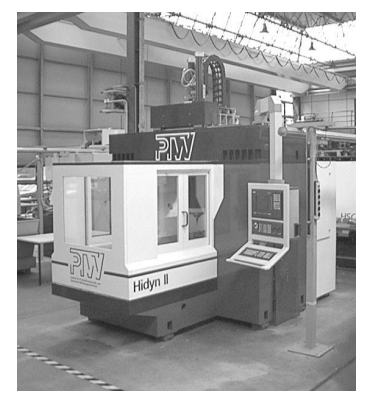

$\begin{array}{ll}\text { Travel X: } & 800 \mathrm{~m} \\ \text { Travel Y: } & 630 \mathrm{~m} \\ \text { Travel Z: } & 500 \mathrm{~m} \\ \text { Max. work piece weight: } & 800 \mathrm{~kg} \\ \text { Rapid traverse: } & 100 \mathrm{~m} / \mathrm{min} \\ \text { max. acceleration: } & 20 \mathrm{~m} / \mathrm{s}^{2} \\ \text { Spindle power: } & 40 \mathrm{~kW} \\ \text { Spindle speed: } & 24.000 \mathrm{U} / \mathrm{min} \\ \text { Tool interface: } & \mathrm{HSK}\end{array}$

Figure 3. High Speed Machine Tool Hidyn II.

Beside the dynamic performance of the machine tool, high natural frequencies and fast machine controls are essential. As the machine control has a large influence on the machining process, the quality of the NC code, that guides the control, influences the result of the machining process and the product as well. Therefore, HSC suitable CAM systems have to yield NC codes, which make use of the optimal machine dynamics and consider all possible drawbacks.

\section{Demands on HSC Suitable CAM Systems}

Especially for the die and mould making industry, where often unique work pieces are machined, the relation between programming and machining time increases, so that the influence of fast calculating systems shows larger benefits. This is particularly important, specially for HSC machining where the step over between the tool paths may be smaller and by this more paths have to be generated. Furthermore, the increase in the accuracy demands raise in the calculation time.

Beside the need for fast CAM systems, the safety of the tool paths must be guaranteed. Collision free paths must be generated, as on the one hand, reaction times for the machinist are shorter with high feed rates. On the other hand, crashes at higher speeds cause more extensive damage to the tool, the spindle and the work piece. Therefore, collision check algorithms have to be used. For the best usability for the operator, the collision checks should be integrated into the CAM system itself. In addition to this, it is important, that not only the tool is included in the collision check. Also the machine geometry like e.g. the spindle or large machine heads have to be considered.

An improved solution for the steadiness of the tool path can be the use of NURBS for the description of the paths (Piegl and Tiller, 1997). If NURBS interpolated NC code is used, the entire NC process chain (CAM systems, postprocessors and $\mathrm{CNCs}$ ) has to support this method. The CAM application has to be able to generate NURBS descriptions, the postprocessor has to be able to translate the NURBS data to suitable NC code and the control of the machine tool must be able to handle the NURBS NC code, which requires up to date machine controls.

Another task to achieve HSC suitable NC programs is to have constant cutting conditions and, therefore, constant loads on the tool. This can be realized by a constant chip geometry over the entire milling process, which can only be obtained, if the CAM system can calculate the non-machined material of the work piece. Beside the evaluation of the residual material for each machining step, it is also necessary that the application can at least display the amount of the material to be machined, so that areas with different offsets can be handled with adjusted strategies by the user. To obtain constant chip geometries, the applications should support automatic adoption of step over distances and of working plane distances, as it is state of the art for the machining of constant scallop heights in finishing operations.

\section{Improvements for CAM Systems}

Further developments of CAM systems offer a wide range for improvements. Beside the optimization of tool path generation algorithms, the automation of the NC programming process should be a target. A first step toward this aim is the integration of knowledge leading to smarter CAM systems. For this, several aspects have to be considered. Beside the above mentioned influences of proper $\mathrm{NC}$ code, the machine control or dynamics of the machine tool, aspects like suitable tools, the work piece material and technological parameters have to be taken into account to achieve best HSC milling results, as shown in Figure 4. The provision of this knowledge in early stages of the production chain to the user can build a foundation for optimized HSC milling results.

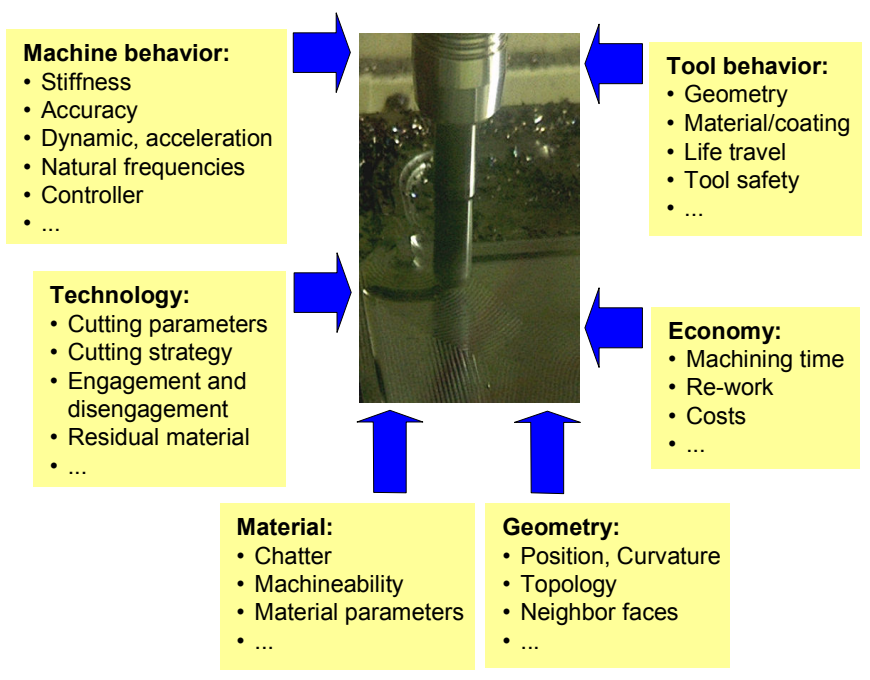

Figure 4. Influences on HSC milling results. 
According to the implemented knowledge base of the CAM system, the user will be assisted at the choice of suitable tools, best cutting speeds and best strategies. A prototype of such an knowledge based, feature oriented CAM system was developed. Figure 5 shows a screenshot of the application, that is based on a commercial CAD/CAM system.

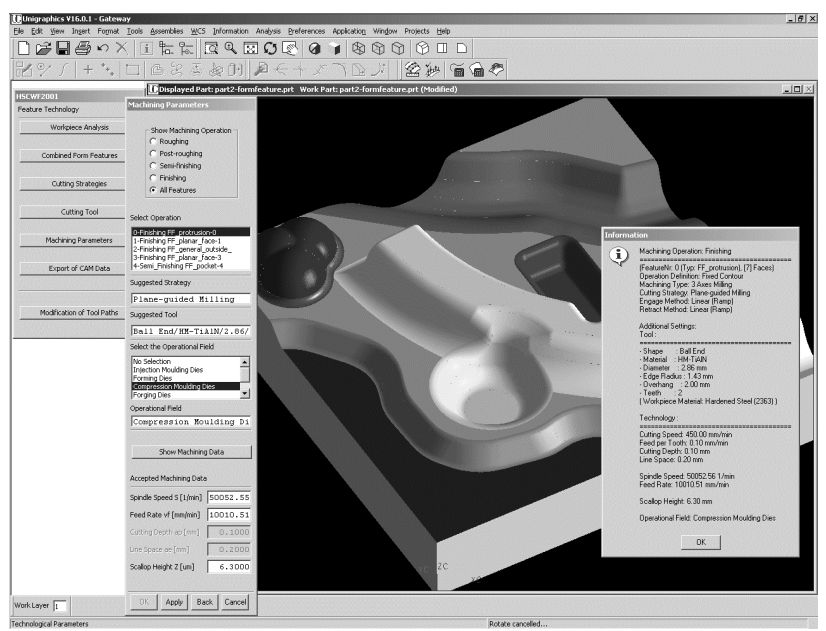

Figure 5. Knowledge integrated CAM system.

\section{HSC Know-How Integration}

The most promising approach for know-how integration is the use of feature technology in the CAD/CAM systems. Features are considered as the best possibility to convey information in an electronic data model (Shah, J.J., Mäntylä, M., 1995). They are defined as (Schützer, 1995), (Schützer, Gardini and Folco, 1998):

"Form Feature is an object, which embodies a semantic, a parametric representation, a technological know-how and can have a geometrical representation" (see Figure 6).

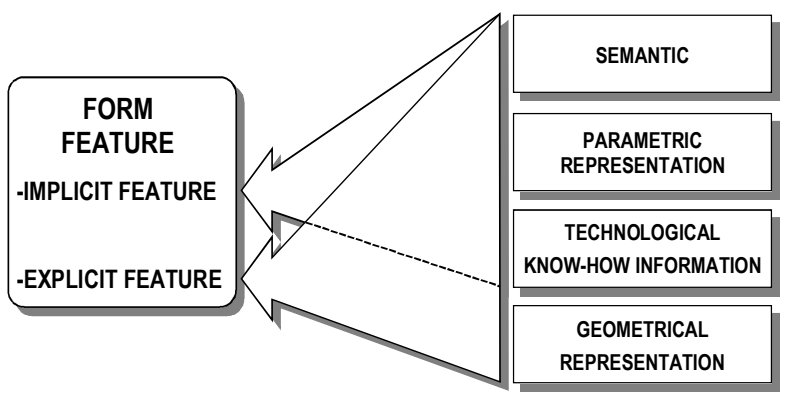

Figure 6. Form feature definition (Schützer, 1995), (Schützer, Gardini and Folco, 1998).

The semantic specifies and characterizes the form feature according to an application. It covers data attributes, rules, methods and relations. In this case the objective is the integration with the downstream CAx systems and to bring to the design phase the manufacturing constraints, that will characterize the project features in manufacturing features.

The technological know-how information makes the feature "intelligent". It triggers methods for the validation of the instantiated features, for the verification of the manufacturability, etc., as well as supports the designers by the input of tolerances, heat treatment specification, etc..

The geometrical representation divides the form features in implicit and explicit features, where the last has a geometric representation.
The parametric representation comprises the construction parameters of a form feature and, in the case of an explicit feature, these parameters are used by the definition of the geometric representation. Different types of features exist. For the described application free form manufacturing features will provide the most benefits.

The final surface roughness of the work piece is directly related to the cutting parameters and cutting strategy chosen during the $\mathrm{NC}$ programming phase. The system can determine for each free form feature the most appropriate cutting strategy according to their curvature, however, the challenge is to combine all these different strategies in a final tool path to machine the whole part and keeping a low surface roughness. The Figure 7 a) exemplifies a situation, where a main strategy was fixed for the whole part, which was not the most appropriate for the features almost placed in vertical position.

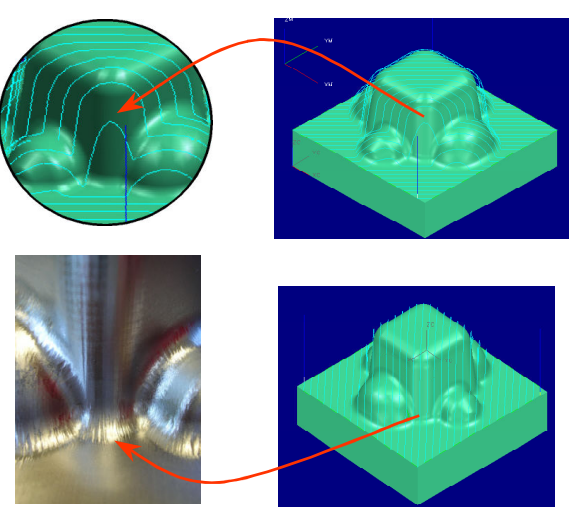

a)

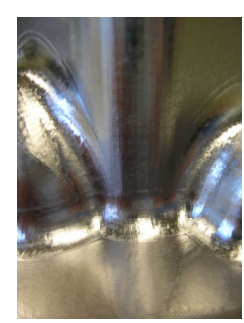

b)
Figure 7. Cutting strategies and surface texture.

Figure $7 \mathrm{~b}$ ) shows de application of different cutting strategies for the lateral surfaces and for the flat surface in the top, which resulted in a lower roughness and better surface texture.

\section{Manufacturing Semantics}

The free form features will be combined with the appropriate machining type. It will enable optimal use of milling, regarding the HSC appropriate machining strategies, cutting tools and technological parameters. This means, that if a planar face is selected, a two axes machining operation with a cylindrical cutter will be selected by the system according to the defined rules and constraints. For a free form feature with slight convex curvature, five axes machining should be used. If the geometry is plane in one direction and has a large curvature in the other direction four axes milling is favorable, because of the higher machining feed rates, which can be reached. But if the curvature is close to zero, and it is not a critical machining condition like steep walls, a $3+2$ axes machining operation is preferable. Only if the geometries are of different nature and/or collisions may occur, three axes milling will be used to achieve an efficient HSC appropriate machining. The most suitable machining type will be an attribute of the free form manufacturing feature.

The HSC appropriate machining starts with the semi-finishing operation because there are no real HSC roughing operations, due to the high power requirements of this operation. Semi-finishing depends on the maximum offset after roughing. To keep the cutting tool as long as possible in the cutting operation the semi-finishing technology is adjusted to the roughing strategy. It will follow the technological knowledge for high speed milling to achieve a surface of high geometric quality as the result of the HSC appropriate 
milling operation, which requires only minor manual finishing. Furthermore for this task the transitions between each of the free form features have to be considered (Schulz and Geist, 1998).

The determination of the HSC appropriate technological parameters is divided into information about the cutting tool, cutting speed, feed rate and in feeds. Depending on the selected free form manufacturing feature, the chosen part material and the machining operation, the knowledge integrated CAM system decides which technological parameter input will be optimal. Cutting parameters, strategy information and optimal tool selection is based on HSC cutting tests (Schulz, 1996) to determine the best parameters according to the selected material and tool. An implementation of this information into the CAD/CAM system is shown in Figure 5.

\section{Definition of HSC Free Form Manufacturing Features}

Besides the technology, strategy and tool geometry, there are additional requirements regarding the information to generate an optimized NC program for HSC. Therefore, the free form manufacturing features have to be extended to HSC free form manufacturing features. These contain knowledge, which creates a safe, reliable and economic HSC machining process. It is required to provide additional knowledge for safety and efficiency. Most of the time the geometric quality of the work piece depends on the experience of the programmer and different knowledge will cause high variance in production results depending on the programmer.

There are several information, which can be calculated in the $\mathrm{CAD} / \mathrm{CAM}$ system before machining to ensure the geometric quality and overcome this deficits. Especially tool wear behavior is one of the most important questions. It depends less on the material and the tool, than on the strategy chosen. Material and the tool cannot be changed, but the machining strategy can be adjusted for the best results. Therefore, a calculation method is needed to supply this before machining. Considering the work done by Finzer, 2001, the expected tool wear using ball end cutters on complex free form surfaces can be estimated. Implementing this calculation in the CAM system using the generated tool path, enables the programmer to evaluate the different tool paths, i.e., cutting strategies concerning the wear of the tool. In addition to this it is possible to calculate when a tool change is necessary (see Figure 8). Especially for large dies and moulds with only little curvature this is a crucial point, because the tool change will leave a mark on the surface, which has to be polished manually. Now with the HSC freeform manufacturing features the exact calculation can shift this point in a visually uncritical area, for example at the beginning of a cutting path.

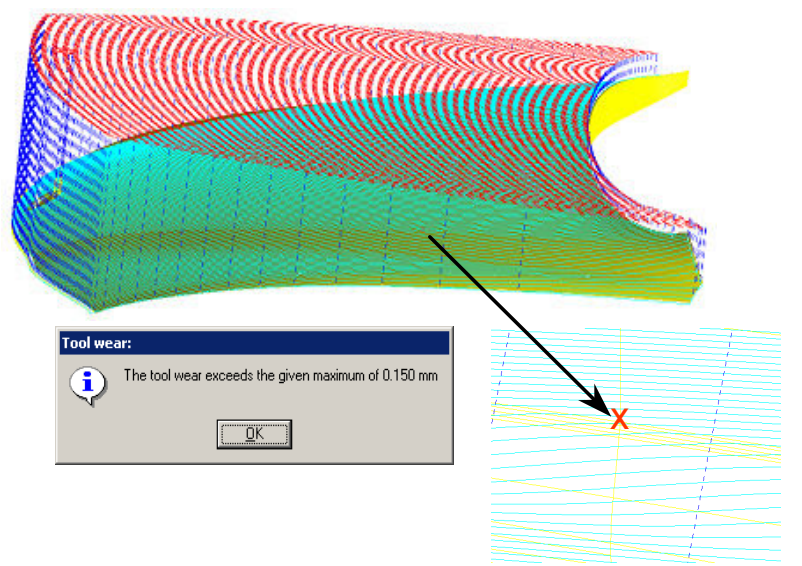

Figure 8. Example of tool change calculation with wear estimation (the cross marks the place, where the tool wear exceeds allowed maximum).
Furthermore safety issues are important for HSC machining. Due to the high speeds the damage caused by collisions is significantly higher than for conventional machining. In addition to this the tool is subject to different load cases regarding centrifugal forces and vibrations. Calculation guidelines dealing with this aspect (Würz, 1999), (Schulz et al., 2000) are essential for efficient HSC programming and so for an efficient machining. So critical situations for the tool, like critical natural frequencies of long slender tools can be detected before machining within the CAM system. This requires safety information to be part of the semantics of HSC free form features. The optimal CAD/CAM system will provide this information to the user during programming.

\section{Conclusion}

Appropriate HSC machining in combination with optimal NC path generation puts a high request on fast CAM programming and HSC knowledge support. A method for higher efficiency of programming is presented in this paper using feature technology, which allows the automatic selection of the best strategy for each feature type. With this the optimal HSC cutting tool path can be programmed in a significantly shorter time, about equal to the time to generate a conventional program.

Furthermore HSC free form manufacturing features are used to convey additional semantics in the CAM system. These will provide the user with information regarding process stability and machining safety. This information can be used directly in the CAM system and can be optimized before and not during the machining. It allows an active improvement of the manufacturing quality considering the geometric aspects of the final part and not just a passive adjustment of parameters at the shop floor, when the efficiency of the process decreases.

\section{References}

Abele, E., Bork, B., 2001, "Vorteile beim Einsatz von Linearmotormaschinen im Werkzeug- und Formenbau", Tagungsband zum 3DErfahrungsforum Werkzeug- und Formenbau, Darmstadt, Germany

Finzer, T., 2001, "Verschleißprognose bei der Hochgeschwindigkeitsbearbeitung mit Kugelkopfwerkzeugen", Dissertation, Darmstädter Forschungsberichte für Konstruktion und Fertigung, TU Darmstadt, Shaker Verlag, Germany

Klocke, F., Markworth, L., Knodt, S., 2001, “Technologietrends aus Anwendersicht", Scope Sonderheft EMO 2001, Germany

Piegl, L., Tiller, W., 1997, “The NURBS Book", Springer Verlag, Berlin, Germany

Schulz, H., Geist, J., 1998, "HSC Appropriate NC-Programming in Die and Mould Manufacturing", Olling, G.J., Choi, B.K., Jerard, R.B. (Pub.), Machining Impossible Shapes: IFIP TC5 WG5.3 International Conference on Sculptured Surface, Kluwer Academic Publishers Group, Dordrecht, The Netherlands, pp. 325-332.

Schulz, H., Huerkamp, W., Fiedler, U., Würz, T., Versch, A., 2000, "Limits for the application of long protruding tools regarding the process stability and safety", Proceedings of the 2nd International Seminar on Improving Machine Tool Performance, La Baule, France

Schulz, H., 2001, "Scientific Fundamentals of HSC", Carl Hanser Verlag, München, Germany

Schützer, K., 1995, "Integrierte Konstruktionsumgebung auf der Basis von Fertigungsfeatures”. Carl Hanser Verlag, München, Germany

Schützer, K.; Gardini, N.; Folco, J.C., 1998, "Basic software tool of the feature modeller for the demonstrator" (Technical Report), INCO-DC \#96-

2161 - FESTEVAL, European Commission, Darmstadt, Germany

Shah, J.J., Mäntylä, M., 1995, "Parametric and Feature-Based CAD/CAM", Wiley-Interscience, New York, USA

Schulz, H., 1996, "Hochgeschwindigkeitsbearbeitung", Carl Hanser Verlag, München, Germany

Würz, T., 1999, "Sicherheit schnelldrehender Fräswerkzeuge", Dissertation, Darmstädter Forschungsberichte für Konstruktion und Fertigung, TU Darmstadt, Shaker Verlag, Germany 